\title{
Substituição Parcial do Farelo de Soja por Uréia e Palma Forrageira (Opuntia fícus indica Mill) em Dietas Para Vacas em Lactação. I. Desempenho ${ }^{1}$
}

\section{Airon Aparecido Silva de Melo², Marcelo de Andrade Ferreira3;6, Antonia Sherlânea Chaves Verás ${ }^{3}$, Mario de Andrade lira $4 ; 6$, Luiz Evandro de Lima ${ }^{4}$, Márcio da Silva Vilela ${ }^{2}$, Elizabel Oliveira Silva de Melo ${ }^{5}$, Paulo Renato Barros Araújo ${ }^{2}$}

\begin{abstract}
RESUMO - O objetivo desse trabalho foi avaliar a substituição parcial do farelo de soja por nitrogênio não protéico no desempenho de vacas holandesas em lactação. Oito animais com 90 dias de lactação e $600 \mathrm{~kg}$ de peso vivo, no início do experimento, foram distribuídos em dois quadrados latinos (4X4). A uréia representou 0,$0 ; 0,8 ; 1,54 ;$ e 2,40\% da matéria seca (MS) da dieta, correspondente a 2,32; 4,$65 ; 6,66$; e 8,02\% de proteína bruta (PB) na forma de compostos nitrogenados-não-protéicos (NNP), que representaram os tratamentos experimentais. O consumo de PB apresentou comportamento quadrático, com valor máximo de 3,3 kg/dia para o nível de 4,71\% de NNP. O consumo de cálcio $(\mathrm{Ca})$ aumentou e o de matéria seca (MS); matéria orgânica (MO); extrato etéreo (EE); carboidratos totais (CHT); carboidratos-não-fibrosos (CNF); fibra em detergente ácido (FDA) e nutrientes digestíveis totais (NDT) diminuíram linearmente, enquanto os consumos de fibra em detergente neutro (FDN) e de fósforo (P) não foram influenciados pelos tratamentos experimentais. As produções de leite sem e com correção para 3,5\% de gordura diminuíram linearmente com a inclusão de uréia e palma forrageira nas dietas. A produção de gordura, proteína, a composição do leite, e a eficiência alimentar (kg de leite/ kg de MS consumida) não foram afetadas pelos níveis de NNP.
\end{abstract}

Palavras-chave: consumo, composição e produção do leite, NNP, proteína

\section{Partial Replacement of Soybean Meal for Urea and Forage Cactus in Lactating Cows Diets. I. Performance}

\begin{abstract}
The work was carried out to evaluate the partial replacement of soybean meal by urea and forage cactus on the performance of lactating dairy Holstein. Eight cows with 90 days in milk and $600 \mathrm{~kg}$ of initial average LW, were assigned in a two 4 $\mathrm{X} 4$ latin square design. The urea represented $0.0,0.8,1.54$ and $2.40 \%$ of dry matter (DM) of the diets, correspondent to $2.32,4.65$, 6.66 and $8.02 \%$ of crude protein (CP) levels in the form of non protein nitrogen compounds (NPN), that represented the experimental treatments. There was a quadratics effect of levels of NPN on the intake of CP, with maximum intake of $3.3 \mathrm{~kg} / \mathrm{day} \mathrm{with} 4.71 \%$ of NPN. The calcium $(\mathrm{Ca})$ intake increased, and dray matter (DM); organic matter $(\mathrm{OM})$, ether extract $(\mathrm{EE})$, total carbohydrates (TCH), non fibercarbohydrates (NFC), acid detergent fiber (ADF) and total digestible nutrients (TDN) intakes decreased linearly. The intakes of neutral detergent fiber (NDF) and Phosphorus (P) was not affected by NPN levels. The milk production and fat corrected milk (3,5\%) decresed linearly as levels of urea and forage cactus increased. The yield of fat, protein, milk composition and feed:eficiency ration was not affected by NPN levels.
\end{abstract}

Key Word: intake, yield and composition of the milk, NPN, protein

\section{Introdução}

A exploração pecuária da região Nordeste é afetada pelas constantes secas e irregularidade das chuvas, impedindo uma exploração racional da atividade leiteira, uma vez que exige uma constância na produção e oferta de alimentos, deste modo, inviabilizando os sistemas tradicionais de produção, restando aos produtores a utilização de alimentos alternativos, adaptados à região, e ou a substituição de fontes dos diferentes nutrientes, especialmente proteína e energia, visando minimizar os custos de produção.

Em relação à adaptação edafo-climática, os produtores vêm utilizando desde a década de 30, as cactáceas Opuntia ssp e Nopalea ssp, como volumoso nos diversos sistemas de produção (Duque, 1980).

Quanto à substituição de fontes protéicas, é prática a utilização de nitrogênio-não-proteico (uréia ou

\footnotetext{
${ }^{1}$ Parte da dissertação apresentada pelo $1^{\circ}$ autor- Financiada pela FACEPE e convênio IPA/UFRPE.

${ }_{2}^{2}$ M.Sc. Zootecnia, aluno do Programa de Doutorado Integrado em Zootecnia - UFRPE/UFC/UFPB

${ }^{3}$ Professores adjunto Departamento de Zootecnia/UFRPE. E.mail: ferreira@ufrpe.br

${ }^{4}$ Pesquisador do IPA.

${ }^{5}$ Zootecnista.

${ }^{6}$ Bolsista CNPq.
} 
cama de galinha). Contudo, quando há substituição do farelo de soja por uréia, considerando-se que a uréia não possui energia, apenas nitrogênio para ser incorporado pelos microrganismos para síntese de proteína microbiana, deve ser incluído na dieta um concentrado energético com baixo teor de proteína (Haddad, 1994).

Tradicionalmente, utiliza-se como concentrado energético o fubá de milho, numa relação de sete partes de milho e uma de uréia, substituindo a mesma quantidade de farelo de soja. Mas, a utilização do fubá de milho como fonte energética, também pode comprometer os custos de produção, por não ser produzido em larga escala no Semi-Árido Pernambucano. Assim, uma alternativa seria a utilização de uma fonte energética de menor custo e disponível na região.

Neste contexto, a palma forrageira (Opuntiafícus indica Mill) é um alimento rico em carboidratos, principalmente carboidratos-não-fibrosos (Wanderley, 2001), que são a principal fonte de energia para os ruminantes (Van Soest, 1994), além de apresentar baixa porcentagem de parede celular, o que a caracteriza como um alimento energético, sem esquecer a sua adaptação às condições edafo-climáticas da região e altas produções de matéria seca por unidade de área (Santos et al., 1997). Neste sentido, Ferreira et al. (2000) substituíram até $75 \%$ do grão de milho moído por farelo de palma em dietas restritas para ovinos em crescimento, e não observaram diferença significativa na digestibilidade dos nutrientes nem no teor de nutrientes digestíveis totais. Araújo (2002) não verificou diferença no desempenho de vacas mestiças em lactação ao substituir todo o milho do concentrado por palma forrageira.

Quando da substituição de alimentos tradicionais, deve-se levar em consideração as mudanças provocadas no comportamento animal, principalmente nível de consumo de alimentos, que segundo Van Soest (1994), é fundamental para a nutrição, pois ele determina o nível de nutrientes ingeridos e, então, a resposta do animal. A ingestão de alimentos depende de vários fatores entre os quais, peso do animal, nível de produção, estádio da lactação, condições ambientais e de manejo, condição corporal, além da composição e qualidade dos alimentos (NRC,1989).

O controle do consumo de alimentos, segundo Raymond, citado por Forbes (1995) é explicado por duas teorias: a da distensão e a quimiostática. Mertens (1994) relata que a ingestão de MS é controlada por fatores fisiológicos, físicos e psicogênicos. O mecanismo físico se refere a distensão do rúmen-retículo, o fisiológico é regalado pelo balanço energético e o psicogênico, este envolve a resposta comportamental do animal, frente a fatores inibidores ou estimuladores no alimento, ou no manejo alimentar.

Colovos et al. (1967), utilizando diferentes níveis de uréia no concentrado para vacas em lactação $(0,0$; 1,$2 ; 2,0$ e 2,5\%), não observaram diferença significativa quanto ao consumo de MS e produção de leite, com e sem correção para $4 \%$ de gordura, em que a uréia representava 0,$0 ; 17,86 ; 30,87$ e $37,93 \%$ da PB da dieta, correspondendo aos valores de 0,0;0,46; 0,78 e $0,99 \%$ de uréia na MS total consumida, ou seja, consumo de uréia variando de 88 a 199 g/dia.

Em outro experimento em que foi utilizada uréia no concentrado, correspondente à variação de 0 a $30 \%$ do nitrogênio total da dieta para vacas em lactação, Plummer et al. (1971), não verificaram influência dos tratamentos sobre a produção de leite com e sem correção para 4\% de gordura; consumo de MS, expresso em \% de PV; e teor de proteína do leite, quando da substituição de equivalente quantidade de nitrogênio oriundo do farelo de soja.

Wilson et al. (1975), estudando os efeitos de níveis crescentes de uréia, em ração completa ou diretamente infundida no rúmen, verificaram que a utilização de uréia acima de $2 \%$ da ração, parece reduzir o consumo, independentemente da forma de fornecimento, porém, a infusão de uréia deprimiu menos o consumo de alimentos do que a uréia fornecida oralmente.

Trabalho desenvolvido por Imaizume et al. (2000), com vacas da raça Holandesa em final de lactação, utilizando farelo de soja ou uréia para obtenção de dois teores de 10 e $13 \%$ de proteína bruta na dieta, com farelo de soja ou uréia, observaram produções médias de $12 \mathrm{~kg}$ de leite/dia. O consumo de matéria seca, produção de leite e eficiência alimentar não foram afetados pelo teor, nem pela fonte de proteína das dietas.

Silva et al. (2001), utilizando níveis também crescentes de uréia em rações completas para vacas mestiças holando-zebu, com níveis de $(0,0 ; 0,7 ; 1,4$; e 2,1\% da MS), correspondendo aos valores dietéticos de compostos nitrogenados-não-protéicos de 2,08; 4,01; 5,76; e 8,07\%, observaram que o consumo de MS, em kg/dia e \% PV; produção de leite corrigido para 3,5\% de gordura; e teor de gordura diminuíram linearmente com o aumento dos teores de NNP nas 
dietas. Os autores concluíram que o menor consumo de MS, provavelmente, foi devido aos efeitos metabólicos da uréia e/ou à pouca palatabilidade do alimento.

Em estudo realizado com vacas da raça Holandesa, utilizando os mesmos níveis de uréia em substituição ao farelo de soja, correspondendo aos valores de compostos nitrogenados-não- protéicos de 2,22; 4,18; 5,96; e 8,09\%, Oliveira et al. (2001) verificaram que o consumo de MS; produção de leite e leite corrigido para 3,5\% de gordura; produções de gordura e proteína; e o teor de proteína do leite diminuíram linearmente, enquanto o teor de gordura e a eficiência alimentar não foram influenciados pelos níveis de NNP nas dietas.

O objetivo do presente trabalho foi estudar os efeitos da substituição de parte do farelo de soja por palma forrageira e uréia (níveis de NNP na dieta) sobre o desempenho de vacas da raça Holandesa.

\section{Material e Métodos}

O experimento foi realizado na Estação Experimental de São Bento do Una, pertencente à Empresa Pernambucana de Pesquisa Agropecuária (IPA), no período de 04 de janeiro a 28 de março de 2001.

Foram utilizadas oito vacas da raça Holandesa, com peso vivo médio inicial de $600 \mathrm{~kg}$ e produção média de $20 \mathrm{~kg}$ de leite/dia. No início do experimento as vacas estavam em média com 91 dias de lactação. Os animais foram mantidos em baias individuais com piso de terra, separadas entre si por cerca de arame farpado, com área coberta de $3 \mathrm{~m}^{2}$, cochos para controle do consumo de alimentos e bebedouro para fornecimento de água. Nos horários mais quentes do dia foi reservado um galpão de alvenaria, coberto com telha de barro, onde os animais permaneceram no período de 10 às $15 \mathrm{~h}$, com acesso apenas à água.

A alimentação foi oferecida duas vezes ao dia, à vontade, às $6 \mathrm{~h}(50 \%)$ e $16 \mathrm{~h}(50 \%)$, na forma de ração completa e, para manter os níveis dos diferentes ingredientes nas rações experimentais, foi permitida sobra de 5 a $10 \%$ do total da MS fornecida, que foi recolhida uma vez por dia antes do fornecimento dos alimentos, pela manhã.

Os tratamentos consistiram de níveis crescentes de nitrogênio-não-protéico (NNP) como porcentagem dos teores de proteína bruta (PB), ou seja, 2,32; 4,$65 ; 6,66$; e $8,02 \%$, resultante da substituição do farelo de soja por palma forrageira mais uréia.

O delineamento experimental foi o quadrado lati- no (4X4), com quatro animais, quatro períodos e quatro níveis substituição do farelo de soja por palma e uréia. Foram utilizados dois quadrados latinos de acordo com a ordem de lactação, um com animais de $5^{\mathrm{a}}$ e o outro de $6^{\mathrm{a}}$ e $7^{\mathrm{a}}$ ordem. Cada período teve duração de 21 dias, sendo 14 dias para adaptação dos animais às rações e 7 dias para coleta de dados e amostras.

As dietas foram formuladas para atender as exigências de produção de $25 \mathrm{~kg}$ de leite/dia com 3,5 $\%$ de gordura e animais com peso vivo de $600 \mathrm{~kg}$, segundo as recomendações do NRC (1989).

Nas Tabelas 1 e 2, são apresentadas a proporção e composição química dos ingredientes das dietas experimentais.

A palma forrageira utilizada foi a Opuntia fícusindica Mill cv. Gigante, e a silagem de sorgo forrageiro Sorghum bicolor (L.) Moench variedade SF-25, da própria Estação Experimental.

Foram realizadas duas ordenhas diárias, às 5 e 15 h, sendo a produção individual de cada animal registrada durante todo período experimental. Nos 60 e $7 \underline{0}$ dia da semana de coleta, foi feita amostragem do leite das duas ordenhas para determinação dos teores de gordura e proteína, utilizando-se o método de Gerber descrito por Behmer (1965), para o teor de gordura, e a metodologia descrita por Silva (1990), para a proteína.

Durante o período de coleta, foram recolhidas amostras da dieta fornecida e das sobras, que foram levadas a estufa de ventilação forçada a $65^{\circ} \mathrm{C}$, para pré-secagem e, armazenadas em sacos, devidamente identificados, para posterior processamento e análises laboratoriais. No final do experimento foi feita uma amostra composta por período e por animal.

As análises foram realizadas nos Laboratórios de Nutrição Animal do Departamento de Zootecnia e de Química do Solo da Universidade Federal Rural de Pernambuco. Para as determinações de matéria seca (MS), proteína bruta (PB), matéria mineral (MM), extrato etéreo (EE), fibra em detergente neutro (FDN) e fibra em detergente ácido (FDA), foram utilizados metodologias descritas por Silva (1990), exceto para determinação da FDN da palma e concentrados, que foi utilizada metodologia proposta por Van Soest et al. (1991) utilizando amilase e uréia a 8 molar e, para determinações de cálcio $(\mathrm{Ca})$ e fósforo $(\mathrm{P})$ a metodologia proposta por Braga \& Defelipo (1974).

Para determinação do nitrogênio-não-protéico (NNP) foi usada metodologia descrita por Sniffen et al. (1992), usando ácido tricloracético a 10\%. Para estimativa dos carboidratos totais (CHT) foi utilizada 
Tabela 1- Proporção dos ingredientes usados nas dietas experimentais, na base da matéria seca e relação volumoso concentrado $(\mathrm{V}: \mathrm{C})$

Table 1 - Ingredients proportion used in the experimental diets, on dry matter basis and roughage: concentrate ratio $(R: C)$

\begin{tabular}{|c|c|c|c|c|}
\hline \multirow[t]{2}{*}{$\begin{array}{l}\text { Ingredientes } \\
\text { Ingredient }\end{array}$} & \multicolumn{4}{|c|}{$\begin{array}{c}\text { \% PB na forma de NNP } \\
\% C P \text { as NPN }\end{array}$} \\
\hline & 2,31 & 4,65 & 6,66 & 8,02 \\
\hline $\begin{array}{l}\text { Silagem sorgo } \\
\text { Sorgum silage }\end{array}$ & 30,44 & 30,64 & 31,20 & 30,98 \\
\hline $\begin{array}{l}\text { Palma forrageira } \\
\text { Forage Cactus }\end{array}$ & 31,94 & 34,93 & 37,77 & 40,88 \\
\hline Uréia & 0,00 & 0,80 & 1,58 & 2,40 \\
\hline $\begin{array}{l}\text { Urea } \\
\text { Fubá de milho } \\
\text { Ground corncraked }\end{array}$ & 14,27 & 14,09 & 13,92 & 13,76 \\
\hline $\begin{array}{l}\text { Farelo de soja } \\
\text { Soybean meal }\end{array}$ & 21,95 & 18,00 & 14,04 & 10,38 \\
\hline $\begin{array}{l}\text { Minerais } \\
\text { Minerals }\end{array}$ & 1,39 & 1,49 & 1,58 & 1,70 \\
\hline $\begin{array}{l}\mathrm{V}: \mathrm{C} \\
R: C\end{array}$ & $62,4: 37,6$ & $65,6: 34,4$ & $69,0: 31,0$ & $71,8: 28,2$ \\
\hline
\end{tabular}

equação proposta por Sniffen et al. (1992), como $\mathrm{CHT}=100-(\% \mathrm{~PB}+\% \mathrm{EE}+\% \mathrm{MM})$ e para estimativa dos carboidratos-não-fibrosos (CNF) foi usada equação proposta por Mertens (1997), como CNF = \%CHT - \%FDN.

A produção de leite foi avaliada através do controle leiteiro diário e o leite corrigido para 3,5\% de gordura por meio da equação proposta por Sklan et al. (1992), PLCG $=(0,432+0,1625 \times$ G) $x$ PL, em que
$\mathrm{G}$ é a porcentagem de gordura do leite e PL, a produção de leite em kg/dia.

Os resultados foram submetidos a análise de variância e regressão, utilizando-se o sistema de análise estatística e genética -SAEG (UFV, 1998). Os critérios utilizados para escolha do modelo foram o coeficiente de determinação $\left(\mathrm{r}^{2} / \mathrm{R}^{2}\right)$ e a significância observada, para o nível de $5 \%$ de probabilidade, pelo teste t.

Tabela 2 - Composição química dos ingredientes das dietas experimentais, com base na matéria seca Table 2 - Chemical composition of experiment ingredient diets, on dry matter basis

\begin{tabular}{|c|c|c|c|c|c|c|}
\hline \multirow[t]{2}{*}{ Item } & \multirow[b]{2}{*}{$\begin{array}{l}\text { Silagem sorgo } \\
\text { Sorghum Silage }\end{array}$} & \multirow[b]{2}{*}{$\begin{array}{l}\text { Palma forrageira } \\
\text { Forage cactus }\end{array}$} & \multicolumn{4}{|c|}{$\begin{array}{l}\text { Ingredientes } \\
\text { Ingredients }\end{array}$} \\
\hline & & & C. 1 & C. 2 & C. 3 & C. 4 \\
\hline$M S^{1}(D M)$ & 31,68 & 10,70 & 88,52 & 87,89 & 87,22 & 86,22 \\
\hline $\mathrm{MO}^{2}(O M)$ & 95,10 & 85,76 & 93,07 & 91,85 & 92,23 & 92,08 \\
\hline $\mathrm{MM}^{2}(M M)$ & 4,87 & 14,24 & 6,92 & 8,14 & 7,76 & 7,91 \\
\hline $\mathrm{PB}^{2}(C P)$ & 5,89 & 5,09 & 33,48 & 37,59 & 42,54 & 46,68 \\
\hline $\mathrm{EE}^{2}(\mathrm{EE})$ & 1,62 & 2,06 & 1,67 & 1,65 & 1,50 & 1,30 \\
\hline $\mathrm{CHT}^{2}(\mathrm{TCHO})$ & 87,62 & 78,60 & 57,92 & 52,61 & 48,19 & 48,39 \\
\hline $\mathrm{CNF}^{2}(\mathrm{NSC})$ & 10,72 & 53,23 & 44,44 & 39,78 & 34,82 & 34,11 \\
\hline $\mathrm{FDN}^{2}(N D F)$ & 76,89 & 25,37 & 13,47 & 12,83 & 13,37 & 14,28 \\
\hline $\mathrm{FDA}^{2}(A D F)$ & 46,69 & 21,79 & 8,53 & 8,55 & 8,06 & 7,65 \\
\hline $\mathrm{NNP}^{3}(N P N)$ & 36,16 & 37,63 & 8,33 & 25,72 & 39,97 & 50,26 \\
\hline $\mathrm{Ca}^{2}(\mathrm{Ca})$ & 0,45 & 2,87 & 0,53 & 0,67 & 0,70 & 1,01 \\
\hline $\mathrm{P}^{2}(P)$ & 0,24 & 0,36 & 0,66 & 0,67 & 0,74 & 0,85 \\
\hline
\end{tabular}

$1 \%(1 \%)$.

$2 \%$ na MS (2 \% of DM).

$3 \%$ de PB; C. concentrado (3\% of CP; C. Concentrate).

R. Bras. Zootec., v.32, n.3, p.727-736, 2003 


\section{Resultados e Discussão}

Na Tabela 3, são apresentados a composição bromatológica e os teores de cálcio (Ca) e fósforo (P) das dietas experimentais, com base na matéria seca (MS).

A porcentagem média de MS das dietas experimentais variou de 46,35 a 38,53\%. Esta variação foi devido à substituição do farelo de soja por uréia e palma, uma vez que a palma contém grande percentual de umidade. A porcentagem de matéria orgânica (MO) depende da quantidade de matéria mineral (MM). Normalmente dietas compostas com palma forrageira apresentam elevado teor de MM devido à alta concentração de macroelementos minerais que a mesma contém. Já a porcentagem de $\mathrm{PB}$ variou de 16 a $17 \%$. Estes valores são maiores do que os recomendados pelo NRC (1989; 2001), cujas exigências dietéticas são de 15,27 e 15,48\% para consumos de 16,5 e 19,51 kgMS/dia, respectivamente, para animais com $600 \mathrm{~kg}$ de peso vivo (PV) e produção de $25 \mathrm{~kg}$ de leite/dia com 3,5\% de gordura.

Devido ao excesso de cálcio $(\mathrm{Ca})$ presente na palma, as dietas apresentaram níveis elevados deste elemento, ficando acima das recomendações dos conselhos citados anteriormente, porém a relação $\mathrm{Ca}: \mathrm{P}$ ficou dentro do limite recomendado para bovinos de leite, cuja amplitude varia de 1:1 a 7:1, segundo o NRC (2001).

As percentagens médias de carboidratos-nãofibrosos (CNF), fibra em detergente neutro (FDN) e fibra em detergente ácido (FDA) verificadas nas dietas experimentais foram de 35,63; 37,33 e 26,03\%, respectivamente. A recomendação do NRC (2001) para dietas com porcentagem de $\mathrm{CNF}$ máximo de $36 \%$, é que contenha um mínimo de FDN de 33\%, sendo 14 a $15 \%$ desta FDN proveniente da forragem; e que apresente valores mínimos de FDA de $21 \%$ da MS, visando favorecer a fermentação ruminal e evitar e depressão da gordura do leite.

As médias referentes aos consumos de MS, expresso em quilograma por dia ( $\mathrm{kg} / \mathrm{dia})$; porcentagem do peso vivo (\% PV); e por unidade de tamanho metabólico (g/ $\mathrm{kg}^{0,75}$ ), e os consumos de MO, EE, PB, $\mathrm{Ca}$ e $\mathrm{P}$, expressos em quilograma por dia ( $\mathrm{kg} / \mathrm{dia})$, com respectivas equações de regressão e coeficiente de variação e determinação são apresentados na Tabela 4.

Ao se elevarem as porcentagens de NNP nas

Tabela 3 - Teor de matéria seca (MS), matéria orgânica (MO), matéria mineral (MM), proteína bruta (PB), percentagem da PB na forma de nitrogênio-não-protéico (NNP), extrato etéreo (EE), carboidratos totais (CHT), carboidratos-não-fibrosos (CNF), fibra em detergente neutro (FDN), fibra em detergente ácido (FDA), nutrientes digestíveis totais (NDT), cálcio (Ca), fósforo $(P)$ e relação $\mathrm{Ca}: P$ das dietas experimentais

Table 3 - Content of dry matter (DM), organic matter (OM), crude protein (CP), average of crude protein as non protein nitrogen (NPN), ether extract (EE), total carbohydrates (TCHO), nonfiber carbohydrates (NSC), neutral detergent fiber (NDF), acid detergent fiber (ADF), total digestible nutrients (TDN), calcium $(\mathrm{Ca})$, phosphorus $(P)$ and $\mathrm{Ca}: P$ ratio of experimental diets

\begin{tabular}{|c|c|c|c|c|}
\hline \multirow[t]{2}{*}{$\begin{array}{l}\text { Ingredientes } \\
\text { Ingredient }\end{array}$} & \multicolumn{4}{|c|}{$\begin{array}{c}\% \text { PB na forma de NNP } \\
\% C P \text { as NPN }\end{array}$} \\
\hline & 2,31 & 4,65 & 6,66 & 8,02 \\
\hline $\mathrm{MS}^{1}(D M)$ & 46,35 & 43,66 & 40,98 & 38,53 \\
\hline $\mathrm{MO}^{2}(O M)$ & 91,35 & 90,68 & 90,68 & 90,56 \\
\hline $\mathrm{MM}^{2} \quad(M M)$ & 8,63 & 9,26 & 9,30 & 9,55 \\
\hline $\mathrm{PB}^{2}(C P)$ & 16,01 & 16,51 & 16,96 & 17,00 \\
\hline $\mathrm{NNP}^{3}(N P N)$ & 2,31 & 4,65 & 6,66 & 8,02 \\
\hline $\mathrm{EE}^{2}(E E)$ & 1,78 & 1,78 & 1,75 & 1,71 \\
\hline $\mathrm{CHT}^{2}(\mathrm{TCHO})$ & 73,39 & 72,39 & 71,97 & 72,94 \\
\hline $\mathrm{CNF}^{2}(N S C)$ & 36,98 & 35,55 & 34,28 & 34,74 \\
\hline $\mathrm{FDN}^{2}(N D F)$ & 36,57 & 36,83 & 37,72 & 38,21 \\
\hline $\mathrm{FDA}^{2}(A D F)$ & 25,67 & 25,77 & 26,23 & 26,46 \\
\hline $\mathrm{NDT}^{2}(T D N)$ & 68,48 & 66,08 & 65,67 & 66,88 \\
\hline $\mathrm{Ca}^{2} \quad(\mathrm{Ca})$ & 1,25 & 1,37 & 1,44 & 1,60 \\
\hline $\mathrm{P}^{2}(P)$ & 0,44 & 0,43 & 0,44 & 0,46 \\
\hline $\mathrm{Ca}: \mathrm{P}(\mathrm{Ca}: P)$ & 2,84: 1,00 & 3,19: 1,00 & $3,27: 1,00$ & $3,48: 1,00$ \\
\hline
\end{tabular}

$1 \%(1 \%)$.

$2 \%$ na MS $(2 \%$ of $D M)$

$3 \%$ de PB; C. concentrado (3\% CP; C. Concentrate). 
dietas, os consumos de MS, nas três formas em que foram expressos, diminuíram linearmente $(\mathrm{p}<0,05)$. Esta redução foi provocada, provavelmente, pelos efeitos metabólicos e/ou a palatabilidade da uréia, devido ao sabor amargo; uma vez que, a quantidade de FDN consumida em $\mathrm{g} / \mathrm{kgPV}$, conforme pode ser visualizado na Tabela 5, ficou abaixo do preconizado pelo modelo FDN-energia, descrito por Mertens (1994), bem como a digestibilidade aparente da MS das dietas experimentais, verificada por Melo (2002), que apresentaram valores entre 70,61 e 67,09\%, o que segundo a teoria de Conrad et al. (1964) limitaria o consumo, apresentando consumo crescente dentro dos tratamentos, caso que não ocorreu e sim o inverso. Vale ressaltar que com a inclusão de NNP ocorreu concomitantemente aumento na proporção de palma forrageira, alimento com elevado teor de umidade, resultando em grande volume de matéria natural, o que, também, poderia contribuir para a redução na ingestão de matéria seca. Neste sentido, Araújo (2002) observou redução no consumo de matéria seca de vacas mestiças em lactação, quando substituiu o milho por palma forrageira.

Similarmente, Oliveira et al. (2001) e Silva et al. (2001) verificaram mesmo comportamento e atribuíram a redução no consumo das dietas com alto nível de NNP aos efeitos metabólicos e sabor amargo da uréia. Mas segundo Roseler et al. (1983) a concentração e a qualidade da proteína também podem influenciar o consumo, alterando tanto o mecanismo físico como o fisiológico. Estes efeitos foram demonstrados em experimento desenvolvido por Wilson et al. (1975), quando utilizaram níveis crescentes de uréia nas dietas ou infundiram uréia diretamente no rúmen e observaram que o consumo em relação ao PV variou de 3,02 a 2,35\% e de 3,22 a 2,65\%, respectivamente, permitindo inferir que os efeitos fisiológicos da uréia deprimiram o consumo de alimentos, quando a uréia foi inoculada no rúmen, e a combinação dos efeitos fisiológicos e psicogênicos, quando do fornecimento via dieta.

Os consumos de MO e EE, expressos em kg/dia, também diminuíram linearmente $(\mathrm{P}<0,05)$ com o aumento dos teores de NNP nas dietas, o que pode ser explicado pela diminuição do consumo de MS. O consumo de PB apresentou comportamento quadrático $(\mathrm{P}<0,05)$, com valor máximo estimado em $3,3 \mathrm{~kg} /$ dia, para o nível de $4,71 \%$ de NNP, o que pode ser explicado pelo aumento da porcentagem de PB nas dietas (Tabela 3) e o tratamento contendo $6,66 \%$ de NNP ter proporcionado maior consumo absoluto de MS em relação aos tratamentos com

Tabela 4 - Médias e equações de regressão dos consumos de matéria seca em kg/dia (CMS), \% PV (CMSPV), e g/kg $\mathrm{kg}^{0,75}$ (CMSTM), matéria orgânica (CMO), extrato etéreo (CEE), proteína bruta (CPB), cálcio (CCa), e fósforo (CP), em kg/dia, em função da porcentagem de PB na forma de nitrogênio não protéico (NNP)

Table 4 - Average and equations regression of the intakes of dry matter in kg/day (IDM); \%BW (IDMBW); and $\mathrm{g} / \mathrm{kg}^{0.75}$ (IDMUTM), organic matter (IOM), ether extract (IEE), crude protein (ICP), calcium (ICa), end phosphorus (IP) in kg/day, as a function of \% CP In the form of non protein nitrogen (NPN)

\begin{tabular}{|c|c|c|c|c|c|c|c|}
\hline \multirow[t]{2}{*}{ Item } & \multicolumn{4}{|c|}{$\begin{array}{c}\% \text { PB na forma de NNP } \\
\% C P \text { as NPN }\end{array}$} & \multirow[t]{2}{*}{$\begin{array}{l}\text { Equações } \\
\text { Equations }\end{array}$} & \multirow[t]{2}{*}{$\mathrm{r}^{2} / \mathrm{R}^{2}$} & \multirow[t]{2}{*}{$\mathrm{CV}$} \\
\hline & 2,31 & 4,65 & 6,66 & 8,02 & & & \\
\hline $\begin{array}{l}\text { CMS } \\
\text { IDM }\end{array}$ & 19,42 & 18,77 & 19,02 & 17,25 & $y=20,2795-0,3125 \mathrm{NNP}$ & 0,77 & 4,32 \\
\hline $\begin{array}{l}\text { CMSPV } \\
\text { IDMBW }\end{array}$ & 3,15 & 3,05 & 3,08 & 2,80 & $y=3,2879-0,0497 \mathrm{NNP}$ & 0,73 & 3,66 \\
\hline $\begin{array}{l}\text { CMSTM } \\
\text { IDMBW }^{0,75}\end{array}$ & 157,05 & 152,66 & 153,50 & 139,4 & $y=163,8890-2,4849 \mathrm{NNP}$ & 0,74 & 3,83 \\
\hline $\begin{array}{l}\text { CMO } \\
\text { IOM }\end{array}$ & 17,83 & 17,09 & 17,26 & 15,63 & $y=18,6712-0,3169 \mathrm{NNP}$ & 0,78 & 4,29 \\
\hline $\begin{array}{l}\mathrm{CEE} \\
I E E\end{array}$ & 0,36 & 0,35 & 0,32 & 0,31 & $\mathrm{y}=0,3851-0,0093 \mathrm{NNP}$ & 0,98 & 8,06 \\
\hline $\begin{array}{l}\mathrm{CPB} \\
\mathrm{ICP}\end{array}$ & 3,20 & 3,24 & 3,23 & 3,02 & $\mathrm{y}=2,8153+0,2037 \mathrm{NNP}-0,0216 \mathrm{NNP}^{2}$ & 0,85 & 5,74 \\
\hline $\begin{array}{l}\mathrm{CCa} \\
\mathrm{Ica}\end{array}$ & 0,24 & 0,26 & 0,26 & 0,28 & $\mathrm{y}=0,2285+0,0062 \mathrm{NNP}$ & 0,87 & 10,8 \\
\hline $\begin{array}{l}\mathrm{CP} \\
I P\end{array}$ & 0,086 & 0,081 & 0,079 & 0,079 & $y=0,0864$ & - & 7,81 \\
\hline
\end{tabular}


4,65 e 8,02\% de NNP. O consumo de Ca aumentou linearmente $(\mathrm{P}<0,05)$ e o de $\mathrm{P}$ não foi influenciado $(\mathrm{P}>0,05)$ pelos teores de NNP das dietas. $\mathrm{O}$ aumento no consumo de $\mathrm{Ca}$ pode ser explicado pelo aumento nos teores de $\mathrm{Ca}$ das dietas à medida que se incluía uréia e palma forrageira em substituição ao farelo de soja (Tabela 3).

Os consumos médios referentes aos CHT, CNF, FDN, expressos em quilograma por dia ( $\mathrm{kg} / \mathrm{dia})$ e porcentagem do peso vivo (\% PV), e os consumos de FDA e NDT, expressos em quilograma por dia $(\mathrm{kg} /$ dia), com respectivas equações de regressão e coeficiente de variação e determinação são demonstrados na Tabela 5 .

Os consumos de CHT, CNF, FDA e NDT, em kg/ dia, foram reduzidos linearmente $(\mathrm{P}<0,05)$ em função dos níveis de NNP das dietas experimentais, o que também pode ser explicado pelo decréscimo no consumo de MS. Quanto ao consumo de FDN, em $\mathrm{kg} / \mathrm{dia}$ e \% PV, não foram observados efeitos ( $\mathrm{P}>0,05)$ dos níveis de NNP, o que pode ser atribuído a concentração crescente da variável FDN nos tratamentos experimentais (Tabela 3), compensando a redução no consumo de MS, e o fator limitante não ter sido o enchimento.

As revisões do NRC (1989 e 2001) preconizam exigências diárias de MS, PB, NDT, Ca e P, para animais com $600 \mathrm{~kg}$ de PV e produção de $25 \mathrm{~kg}$ de leite/dia com 3,5\% de gordura, de 16,50 e $19,51 \mathrm{~kg}$; 2,51 e $3,02 \mathrm{~kg} ; 11,76$ e $11,82 \mathrm{~kg} ; 0,098$ e $0,121 \mathrm{~kg}$; e 0,062 e $0,067 \mathrm{~kg}$, respectivamente.

Os consumos médios de PB, NDT, Ca e P, dos tratamentos experimentais, atenderam às exigências preconizadas pelas revisões do NRC referendadas, exceto o tratamento com nível 8,02\% de NNP, que em relação ao consumo de NDT ficou um pouco abaixo da recomendação dos referidos Conselhos (Tabelas 4 e 5).

As médias referentes à produção de leite com e sem correção para 3,5\% de gordura, expressas em quilograma por dia $(\mathrm{kg} / \mathrm{dia})$, gordura e proteína, expresso em grama por dia (g/dia) e teores de gordura e proteína, expressos em porcentagem (\%), além da eficiência alimentar (EA), expressa em $\mathrm{kg}$ de leite produzido/kg de MS consumida, com respectivos coeficientes de determinação e variação são mostrados na Tabela 6.

As PL e PLCG, em kg/dia, diminuíram linearmente $(\mathrm{P}<0,05)$ com o aumento dos níveis de NNP da dieta. Esta redução na produção poderia ser explicada pela menor ingestão de MS, já discutida anteriormente.

Resultados contrários a estes foram verificados por Colovos et al. (1967), que não observaram diferença quanto à produção de leite, quando utilizaram até $2,5 \%$ de uréia no concentrado e produção média de $26,92 \mathrm{~kg}$ de leite/dia. Contudo a quantidade

Tabela 5 - Médias e equações de regressão dos consumos de carboidratos totais (CCHT), carboidratos não fibrosos (CCNF), fibra em detergente neutro (CFDN), em kg/dia e \% PV (CFDNPV), fibra em detergente ácido (CFDA) e nutrientes digestíveis totais (CNDT), em kg/dia, em função da porcentagem de PB na forma de nitrogênio-não-protéico (NNP)

Table 5 - Average and equations of regression of the intakes of total carbohydrates (TCHO), nonfiber carbohydrate (NSC), neutral detergent fiber (NDF), in $\mathrm{kg} /$ day and \% BW, acid detergent fiber (ADF) and total digestible nutrients (TDN), in $\mathrm{kg} /$ day, as a function of $\%$ CP in the form of non protein nitrogen (NPN)

\begin{tabular}{|c|c|c|c|c|c|c|c|}
\hline \multirow[t]{2}{*}{ Item } & \multicolumn{4}{|c|}{$\begin{array}{c}\text { \% PB na forma de NNP } \\
\text { \% CP as NPN }\end{array}$} & \multirow[t]{2}{*}{$\begin{array}{c}\text { Equações } \\
\text { Equations }\end{array}$} & \multirow[t]{2}{*}{$\mathrm{r}^{2} / \mathrm{R}^{2}$} & \multirow[t]{2}{*}{$\mathrm{CV}$} \\
\hline & 2,31 & 4,65 & 6,66 & 8,02 & & & \\
\hline $\begin{array}{l}\text { CCHT } \\
\text { ITCHO }\end{array}$ & 14,18 & 13,40 & 12,99 & 12,46 & $\mathrm{y}=14,8282-0,2896 \mathrm{NNP}$ & 0,98 & 7,33 \\
\hline $\begin{array}{l}\text { CCNF } \\
\text { INSC }\end{array}$ & 7,74 & 7,24 & 6,62 & 6,67 & $\mathrm{y}=8,1733-0,2046 \mathrm{NNP}$ & 0,87 & 7,95 \\
\hline $\begin{array}{l}\text { CFDN } \\
I N D F\end{array}$ & 6,44 & 6,16 & 6,46 & 5,79 & $\mathrm{y}=6,5870$ & - & 7,45 \\
\hline $\begin{array}{l}\text { CFDNPV } \\
I N D F B W\end{array}$ & 1,04 & 1,00 & 1,08 & 0,94 & $\mathrm{y}=1,0671$ & - & 7,11 \\
\hline $\begin{array}{l}\text { CFDA } \\
I A D F\end{array}$ & 4,68 & 4,40 & 4,56 & 4,20 & $\mathrm{y}=4,8099-0,0609 \mathrm{NNP}$ & 0,49 & 6,03 \\
\hline $\begin{array}{l}\text { CNDT } \\
\text { ITDN }\end{array}$ & 13,30 & 12,40 & 12,49 & 11,53 & $y=13,8739-0,2678 \mathrm{NNP}$ & 0,86 & 4,27 \\
\hline
\end{tabular}


Tabela 6 - Médias e equações de regressão da produção de leite (PL), produção de leite corrigido para $3,5 \%$ de gordura (PLCG), em kg/dia, teores de gordura $(G)$ e proteína do leite $(P)$, em $\%$, e produções de gordura ( $P G)$ e proteína (PP), em g/dia, e eficiência alimentar (EA) em $\mathrm{kg}$ de leite / $\mathrm{kg}$ MS consumida, em função da porcentagem de PB em forma de nitrogênio não protéico (NNP)

Table 6 - Average and equations of regression of the milk production (MP), milk production corrected for $3,5 \%$ fat $(M P C)$ in $\mathrm{kg} /$ day, contents of milk fat $(F)$ and protein $(P)$, in $\%$ and fat $(F P)$ and protein $(P P)$ production, in g/day, and, feed efficiency (FE), in $\mathrm{kg}$ milk/ $\mathrm{kg} D M$, as a function of \% CP in the form of non protein nitrogen (NPN)

\begin{tabular}{|c|c|c|c|c|c|c|c|}
\hline \multirow[t]{2}{*}{ Item } & \multicolumn{4}{|c|}{$\begin{array}{c}\text { \% PB na forma de NNP } \\
\% C P \text { as NPN }\end{array}$} & \multirow[t]{2}{*}{$\begin{array}{l}\text { Equações } \\
\text { Equations }\end{array}$} & \multirow[t]{2}{*}{$\mathrm{r}^{2} / \mathrm{R}^{2}$} & \multirow[t]{2}{*}{$\mathrm{CV}$} \\
\hline & 2,31 & 4,65 & 6,66 & 8,02 & & & \\
\hline $\mathrm{PL}(M P)$ & 19,36 & 18,94 & 17,87 & 17,82 & $y=20,0745-0,2924 \mathrm{NNP}$ & 0,90 & 6,55 \\
\hline $\operatorname{PLCG}(M P C)$ & 18,81 & 18,57 & 18,15 & 17,50 & $\mathrm{y}=19,4474-0,2250 \mathrm{NNP}$ & 0,97 & 6,48 \\
\hline $\mathrm{G}(F)$ & 3,41 & 3,40 & 3,65 & 3,43 & $\mathrm{y}=3,3748$ & - & 7,19 \\
\hline $\mathrm{PG}(F P)$ & 660,17 & 643,96 & 652,25 & 611,22 & $y=667,6560$ & - & 8,57 \\
\hline $\mathrm{P}(P)$ & 3,49 & 3,36 & 3,22 & 3,37 & $y=3,5327$ & - & 7,71 \\
\hline $\mathrm{PP}(P P)$ & 675,66 & 636,38 & 575,71 & 600,53 & $y=677,0470$ & - & 11,19 \\
\hline $\mathrm{EA}(F E)$ & 0,99 & 1,00 & 0,94 & 1,03 & $y=0,9545$ & - & 6,12 \\
\hline
\end{tabular}

de uréia na dieta foi de $0,99 \%$ da MS total. Imaizume et al. (2000), trabalhando com vacas da raça Holandesa no final de lactação, e produções médias de 12 $\mathrm{kg} /$ dia, também não observaram diferença na produção quando utilizaram uréia ou farelo de soja e teores de proteína diferentes (10 e 13\%), respectivamente. Por outro lado, Huber et al. (1967) encontraram produções decrescentes de 23,3 a 16,40 e variação do peso vivo (VPV) de 0,23 a $-0,33 \mathrm{~kg} /$ dia, quando a uréia substituiu parcial ou totalmente a proteína natural da dieta. Oliveira et al. (2001) e Silva et al. (2001) também verificaram queda na produção de 20,11 a 17,50 e 21,18 a 18,83 kg/dia, respectivamente, quando utilizaram teores de uréia de 0,0 a 2,1\% da MS da dieta. Permitindo inferir que as respostas produtivas em função do acréscimo de NNP na dieta de vacas lactantes são variáveis, pois quando o nível de inclusão de uréia é baixo e as produções de leite altas ou o inverso, não há interferência do aumento de uréia sobre a produção de leite. Contudo, em dietas cujo percentual de uréia é superior a $2 \%$ do total de MS, e produções próximas de $20 \mathrm{~kg} / \mathrm{dia}$, ocorre redução na produção.

O NRC (2001) recomenda para produções de 25 $\mathrm{kg}$ de leite com 3,5\% de gordura, relação de proteína degradada(PDR) e proteína-não-degradada no rúmen (PNDR) de 60:40\%. Estes resultados decrescentes na PL e PLCG devem-se, provavelmente, ao excesso de PDR, causado pelo aumento de uréia nas dietas, ultrapassando os limites recomendados pelo NRC (2001). As concentrações de PDR estimadas, para os tratamentos experimentais, considerando a palma forrageira, cultivar gigante com $66,3 \%$ de degradabilidade efetiva da proteína segundo Santos et al. (2000), e os valores tabelados de Campos et al. (1995) e Lana (2000) para os demais alimentos utilizados, foram de 54,86; 60,70; 65,98; e 71,00\% do total da proteína consumida, correspondentes aos tratamentos 2,$31 ; 4,65 ; 6,66$; e $8,02 \%$ de NNP, respectivamente.

As produções e os teores de gordura e proteína bruta do leite, expressos em $\mathrm{g} / \mathrm{dia}$ e porcentagem, não foram influenciados $(\mathrm{P}>0,05)$ pelos níveis de NNP na dieta. Em relação à composição, esta ausência de significância pode ser explicada pelo correto balanceamento dos carboidratos estruturais e não fibrosos, como também pelos níveis adequados de $\mathrm{PB}$, uma vez que estes, são os principais responsáveis pelos fatores nutricionais que modificam os teores de proteína e gordura do leite (Fredeen, 1996).

Contrariamente, Silva et al. (2001) encontraram efeito linear decrescente na \% da gordura e efeito quadrático para $\%$ de proteína bruta, quando utilizaram níveis crescentes de NNP na dieta. Já Oliveira et al. (2001) não observaram diferença quanto ao teor de gordura e decréscimo linear no teor de proteína do leite, utilizando os mesmos níveis de NNP.

A eficiência alimentar (EA) não foi afetada $(\mathrm{P}>0,05)$ pelos níveis de NNP das dietas experimentais, apresentando, em média, produção de $0,99 \mathrm{~kg}$ leite/ kg MS consumida.

Esta EA foi inferior a observada por Oliveira et al. (2001), com média de 1,21, quando da 
substituição de parte do farelo de soja por uréia e milho, na dieta de vacas da raça Holandesa com PV de $450 \mathrm{~kg}$. Wanderley (2001), substituindo a silagem de sorgo por níveis crescentes de palma forrageira em dietas para vacas da raça Holandesa, utilizando uma relação volumoso/concentrado de 57:43, observou EA crescentes variando de 1,20 a 1,29.

Apesar de o peso vivo dos animais não ter sido analisado estatisticamente, ocorreu variação positiva do PV, com média diária de $0,22 \mathrm{~kg}$, durante o período experimental. Esta variação não foi uniforme para todos os tratamentos, apresentando os maiores valores para o nível com $2,31 \%$ NNP e o menor valor para o nível com $8,02 \%$ de NNP, acompanhando as mesmas tendências do consumo e produção.

Diferentemente do relato de Santana et al. (1972), em que os animais apresentaram repetidas diarréias e pobre ruminação, quando alimentadas com grande quantidade de palma forrageira, e diarréia não patológica (Santos et al., 1997), no presente experimento não foi verificado nenhum dos sintomas descritos anteriormente, mesmo com a inclusão de $40,88 \%$ de palma na MS da dieta.

Os nutrientes consumidos foram suficientes para as produções observadas e, ainda variação positiva do peso. Vale salientar que estes nutrientes poderiam ser utilizados para maiores produções, pois a fase em que os animais experimentais se encontravam não seria a mais apropriada para recuperação do escore corporal.

Os custos das dietas na época da realização do experimento, foram de $\mathrm{R} \$ 0,26 ; 0,24 ; 0,23$ e 0,21 por $\mathrm{kg}$ MS, ao mesmo tempo em que o $\mathrm{kg}$ de leite era vendido a R \$ 0,30. Portanto, a relação custo/beneficio comprometeu $86,70 \%$ da renda com a alimentação no tratamento contendo $2,31 \%$ de NNP, enquanto o tratamento com $8,02 \%$ de NNP comprometeu $70,00 \%$.

\section{Conclusões}

Níveis elevados de nitrogênio-não-proteíco (NNP) nas dietas de vacas em lactação influenciam negativamente o desempenho animal, sem, contudo, afetar a produção e os teores de gordura e proteína bruta do leite, nem a eficiência alimentar.

A inclusão de NNP não afetou a saúde dos animais e baixou os custos das dietas, portanto para recomendação da utilização de fontes de NNP na alimentação de vacas em lactação, devem ser avaliados também os aspectos econômicos.

\section{Literatura Citada}

ARAÚJO, P.R.B.Substituição do milho por palma forrageira (Opuntia fícus indica Mill eNopalea cochenilliferaSalmDyck) em dietas completas para vacas em lactação. Recife: Universidade Federal Rural de Pernambuco, 2002. 43p. Dissertação (Mestrado em Zootecnia) - Universidade Federal Rural de Pernambuco, 2002.

BRAGA, J.M.; DEFELIPO, B.V. Determinação espectrofotometrica de fósforo em extratos de solos e plantas. Revista Ceres, v.21, p.73-75, 1974.

BEHMER, M.L.A. Laticínios, leite, manteiga, queijo, caseína e instalações. 3.ed. São Paulo: Melhoramento, 1965. 294p.

CAMPOS, O.F.; LIZIEIRE, R.S.; DAYRELL, M.S. et al.Características e composição de alguns alimentos concentrados utilizados na alimentação de bovinos de leite. EMBRAPA/CNPGL, 1995. 29p. (Circular técnica, 38).

COLOVOS, N.F., HOLTER, J.B., DAVIS, H.A. et al. Urea for lactating dairy cattle. II effect of various levels of concentrate urea on nutritive value of the ration. Journal of Dairy Science, v.50 n.4, p.523-526, 1967.

CONRAD, H.R.; PRATT, A.D.; HIBS, J.W. Regulation of feed intake in dairy cows. 1-Change in importance of physical and physiological factores with increasing digestibility.Journal of Animal Science, v.47, n.1, p. 54-62, 1964.

DUQUE, J.G. O Nordeste e as lavouras xerófilas. 3.ed. Mossoró: ESAM, 1980. 316p. (Coleções Mossoroienses; 143).

FERREIRA, M.A.; VERAS, R.M.L.; CARVALHO, F.F.R. et al. Substituição parcial do milho moído pelo farelo de palma, como fonte de energia para ruminantes: Consumo e digestibilidade aparente dos nutrientes. In: CONGRESSO NORDESTINO DE PRODUÇÃO ANIMAL, 2., 2000, Teresina. Resumos...Teresina: 2000. p.340-342.

FORBES, J. M. Voluntary food intake and diet selection by farm animals: Madison: $C A B$ international, 1995. 532p.

FREDEEN, A.H. Considerations in the nutritional modification of milk composition. Animal Feed Science and Technology, v.59, p.185-197, 1996.

HADDAD, C.M. Uréia em suplementação alimentares. In: SIMPOSIO NORDESTINO DE ALIMENTAÇÃO DE RUMINANTES, 2., 1994, Piracicaba.Resumo...Piracicaba; 1994. p.306.

HUBER, J.T.; SANDY, R.A.; POLARY, C.E. et al. Varying levels of urea for dairy cows fed corn silage os the only forage. Journal of Dairy Science, v.50, n.8, p.1241-1247, 1967.

IMAIZUME, H.; SANTOS, F.A.P.; PIRES, A.V. et al. Efeito de dois teores de proteína bruta proveniente de farelo de soja e/ ou uréia sobre o desempenho de vacas leiteiras em final de lactação. In: REUNIÃO ANUAL DA SOCIEDADE BRASILEIRA DE ZOOTECNIA, 37., 2000, Viçosa, MG.Anais... Viçosa: Sociedade Brasileira de Zootecnia, 2000. p.578.

LANA, R.P.Sistema viçosa de formulação de rações.Viçosa, MG: Universidade Federal de Viçosa, 2000. 60p.

MERTENS, D.R. Regulation of forage intake. In:Foragequality evaluation and utilization. FAHEY Jr., (Ed.) Madison: American Society of Agronomy, 1994. p.450-493.

MERTENS, D.R. Creating a system for meeting the fiber requirements of dairy cows. Journal of Dairy Science, v.80, n.7, p.1463-1481, 1997.

NATIONAL RESEARCH COUNCIL - NRC. Nutrient requirements of the dairy cattle. 6.ed. Washington: D.C.: 1989. $158 \mathrm{p}$. 
NATIONAL RESEARCH COUNCIL - NRC. Nutrient requirements of the dairy cattle. 7.ed. Washington: D.C.: 2001. 363p.

OLIVEIRA, A.S.; VALADARES, R.F.D.; VALADARES FILHO, S.C. et al. Consumo, digestibilidade, produção e composição do leite em vacas alimentadas com quatro níveis de compostos nitrogenados não-protéicos. Revista Brasileira de Zootecnia, v.30, n.4, p.1358-1366, 2001.

PLUMMER, J.R.; MILES, J.T.; MONTGOMERY, M.J. Efect of urea in the concentrate mixture ou intake and production of cows fed corn silage as the only forage. Journal Dairy Science, v.54, n.12, p.1861-1865, 1971.

ROSELER, DK., FERGUNSON, J.D., SNIFFEN, C.J. et al. Dietary protein degradability efeects on plasma and milk urea nitrogen and milk non-protein nitrogen in holstein cows. Journal of Dairy Science, v.76, n.2, p.525-534, 1993.

SANTOS, D. C. et al. A palma forrageira (opuntia fícusindica Mill e Nopalea cochenillifera Salm Dyck) em Pernambuco: Cultivo e utilização: Recife: IPA, 1997. 23p. (Documentos, 25)

SANTOS, G.R.A.; BATISTA, A.M.V.; CARVALHO, F.F.R. et al. Composição química e degradabilidade da matéria seca de dez clones de palma forrageira (Opuntia e Nopalea). In: REUNIÃO ANUAL DA SOCIEDADE BRASILEIRA DE ZOOTECNIA, 37., 2000, Viçosa, MG. Anais... Viçosa, MG: Sociedade Brasileira de Zootecnia, 2000. (CD ROM)

SANTANA, O.P.; VIANA, S.P.; ESTIMA, A.L. et al. Palma versus silagem na alimentação de vacas leiteiras. Revista brasileira de Zootecnia, v.1, n.1, p.31-40, 1972.

SNIFFEN, C.J.; O'CONNOR, J.D.; Van SOEST, P.I. et al. A net carboydrate and protein system fort evaluating cattle diets. II carboydrate and protein availability. Journal of Dairy Science, v.70, p.3562-3577, 1992.

SILVA, D.J. Análise de alimentos (métodos químicos e biológicos). Viçosa, MG: Unviersidade Federal de Viçosa, 1990. 165p.
SILVA, R.M.N.; VALADARES, R.F.D.; VALADARES FILHO, S.C. et al. Uréia para vacas em lactação. 1 consumo, digestibilidade, produção e composição do leite. Revista Brasileira de Zootecnia, v.30, n.5, p. 1639-1649, 2001.

SKLAN, D.; ASHKENAZI, R.; BRAUN, A. et al. Fatty acids, cacium soaps of fatty acids and cottonseeds fed to high yielding cows. Journal of Dairy Science, v.75, n.70, p.2463-2472, 1992.

Van SOEST, P.J.; ROBERTSON, J.B.; LEWIS, B.A. Methods for extraction fiber, neutral detergent fiber and mostarch polysaccarides in relation to animal nutrition cows.Journal of Dairy Science, v.83, n.1, p.3583-3597, 1991.

VAN SOEST, P.J. Nutrional ecology of the ruminant. 2.ed. New York: Cornell University Press, 1994. 476p.

UNIVERSIDADE FEDERAL DE VIÇOSA - UFV. SAEG Sistema de análise estatística e genética. versão 8.0. Viçosa-MG (manual do usuário), 1998. 150p.

WANDERLEY, L.W.Palma forrageira (Opuntia ficus indica Mill) em substituição à silagem de sorgo (L.) Moench) na ração de vacas Holandesas em lactação. Recife: Universidade Federal Rural de Pernambuco, 2001. 41p. Dissertação (Mestrado em Zootecnia) - Universidade Federal Rural de Pernambuco, 2001.

WILSON, G.; MARTZ, F.A.; CAMPBELL, J.R. et al. Evaluation of factores responsible for reduced voluntary intake of urea diets for ruminants. Journal of Dairy Science, v.41, n.5, p.1431-1437, 1975.

Recebido em: 20/05/02

Aceito em: $05 / 11 / 02$ 